\title{
A SEMÂNTICA HISTÓRICA: UM CAMPO ABANDONADO DA LINGÜÍSTICA?*
}

Wolfgang Roth ${ }^{* *}$

RESUMO: Trata-se de definir o campo da Semântica, apontando a sua trajetória desde os estudos iniciais, ligados aos da etimologia e da gramática histórica. São expostas as razões de prevalecer, na semântica tradicional, o enfoque lexical, discutindo-se também a questão do referente, excluído nos estudos estruturalistas, mas reintroduzido pelas teorias contemporâneas. Do exame das tendências atuais mais importantes - destacando-se a teoria dos protótipos como parte da linguiística cognitiva - chega-se a aproximações com a semântica histórica. As chamadas "vias evolutivas" seriam regidas por um saber enciclopédico e pela capacidade humana de categorização. Igualmente, ressurge a preocupação da semântica histórica com o léxico e com a polissemia, porém recolocada dentro da função comunicativa da linguagem humana.

Palavras-chave: significado/significação, referente, semântica lexical/semântica histórica.

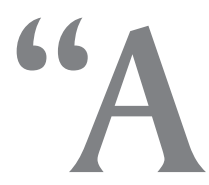

semântica é um domínio de investigação de limites movediços". Esta definição, que não parece ser nenhuma, encontra-se no livro intitulado Semântica, de Rodolfo Ilari e João Wanderley Geraldi. Esta "indefinição" comprova-se facilmente mediante uma comparação do conteúdo deste livro introdutório com um clássico da semântica, o manual de Stephen Ullmann, publicado uns 25 anos antes. Mesmo que se tomasse em conta o progresso da semântica neste último quarto de século e o fato de os dois semanticistas brasileiros não tratarem da semântica histórica, à qual Ullmann dá um vasto lugar, a discrepância entre estas duas

\footnotetext{
Texto correspondente a conferência ministrada no dia 12/09/97 na Universidade de São Paulo.

* Universidade de Bochum, Alemanha, e Valenciennes, França.
} 
publicações ficaria inexplicável. É certo que na linguiística surgiram novos conceitos e métodos, novos enfoques na sintaxe, termos como texto, contexto ou co-texto, que antes haviam desempenhado um papel secundário, ao passo que o léxico perdeu a sua importância como elemento central que teve nas pesquisas linguiísticas históricas. Mas, a fim de que se compreenda por que a semântica significa algo diferente para Rodolfo Ilari e João Wanderley Geraldi do que significava para Bréal ou Ullmann, é preciso partir do próprio fato linguiístico que está na base da semântica e que dispõe de várias designações.

Em outras introduções à semântica pode-se ler que a dificuldade de definir o objeto desta área da linguiística consiste na imprecisão do termo, que se refere aos elementos a serem estudados na semântica. De fato, temos à disposição, para estes elementos, diferentes designações: sentido, significado, significação, acepção, conteúdo. Mas esta variedade reflete antes os diferentes enfoques aplicados ao objeto da semântica do que uma incerteza no tratamento do assunto. Os linguiistas sempre têm sido conscientes do fato de o objeto de suas preocupações poder-se dividir em duas abordagens, partindo do lado material, audível e visível da linguagem e do seu lado imaterial, isto é, do lado espiritual, reconhecível e compreensível. A terminologia é que tem vacilado, refletindo-se numa visão dicotômica, seja esta chamada expressão e conteúdo, onomasiologia e semasiologia ou significante e significado. Se a consciência do lado significativo da linguagem forma parte integrante de qualquer pensamento linguiístico, duas perspectivas fazem com que a semântica tenha estado sujeita a avaliações diferentes no decorrer da história da linguiística: a sua importância e posição dentro da análise linguíśstica e a praticabilidade científica do conceito significado. Enquanto o significado serviu apenas de critério para a análise e classificação dos elementos significantes da linguagem, o interesse no significado consistiu em dispor de uma unidade fixa para o estudo do lado material, mas não importava em si. Assim, a grande maioria dos estudos filológicos do século XIX se dedicou prioritariamente ao significante. E mesmo quando a semântica se cons- 
tituiu como área de pesquisas autônoma, a linguiística, durante muito tempo, preferiu concentrar-se no significante. Testemunham isto tanto a gramática histórica como a dialetologia e a geografia linguiística. Praticamente nenhuma gramática histórica - exceto a de Nyrop para o francês - abrangia a semântica ou "chegava" até esta. Na geografia linguística o enfoque onomasiológico dominou quase completamente. Talvez o único campo onde, na linguíística pré-estruturalista, a semântica encontrou um valor igual ao estudo do lado significante da língua, tenha sido a estilística.

Uma das razões da dificuldade de encontrar um termo único e abrangente para o elemento a analisar na semântica é provavelmente o fato de este constituir um conceito muito geral e carente de uma diferenciação comparável à do lado significante, onde conhecemos toda uma gama de unidades, a começar pelo morfema flexivo e derivativo e a terminar com os conceitos de oração e texto. Quando estudamos o lado significante da língua, estamos praticamente forçados a determinar o elemento que estudamos: morfema flexivo, morfema derivativo, lexema, oração, etc. Todas estas unidades se definem, é claro, pelo seu lado significativo, mas o que neste contexto importa é que se parte do significante e que normalmente o critério semântico serve apenas de meio de classificar os elementos significantes. Uma classificação que toma como ponto de partida o significado e distingue, por exemplo, entre sememas gramaticais, derivativos, composicionais, sintagmáticos, oracionais e textuais parece ser inerente aos estudos semânticos, mas raros são os casos em que, desde o início dos estudos semânticos, existe a consciência desta distinção. O começo histórico da semântica localiza-se no léxico, na palavra, ao passo que as outras unidades do nível dos significantes apenas mais tarde despertaram um interesse linguiístico. A razão deste caminho tomado pela semântica no século XIX está no caráter particular do lexema que, mais do que as outras unidades de significado, representa uma espécie de dicotomia que ressalta quando se recorre ao famoso triângulo de Ogden e Richards. 
Por simplista que seja este triângulo, ele indica um lado relacionado com o semântico, sempre presente aos estudiosos, mas negligenciado ou mal-avaliado deste o início e, não raro, excluído sob o impacto da doutrina saussuriana, que pretende limitar-se ao puramente linguiístico das suas teorias. Trata-se da noção do referente.

O semanticista Andreas Blank (Blank, 1993, p. 63) mostrou que na semântica tradicional - e inclusive na semântica clássica de Stephen Ullmann - uma parte da classificação das causas da mudança semântica se baseava não no significado, mas no referente. É o caso da metáfora e da metonímia. Ora, como já se disse, em toda a semântica tradicional prevalece a semântica lexical. A explicação de certas mudanças pelo contexto gramatical, apresentada, por exemplo, por Antoine Meillet sob a designação de "causas linguiísticas", constitui antes uma exceção.

Queira-se ou não incluir o referente da semântica, de qualquer maneira não se deve esquecer que o referente pode ser de natureza vária. Podemos distinguir pelo menos dois referentes que poderiam ser chamados de referente-realidade e referente-categoria. Parece que é o referente que pode estar na base de uma caracterização do elemento semântico, porque, no fundo, temos dois referentes de natureza bastante diferente: enquanto o primeiro está ligado à chamada realidade extralinguiística, sendo, portanto, de classificação difícil, o segundo se baseia exclusivamente no pensamento linguiístico-gramatical, não sem haurir as noções também na chamada realidade extralinguiística. Os significados lexicais orientam-se pelo mundo que parece fugir da estrutura da língua. Coseriu (1964, p. 144) sublinha que a criação de uma terminologia conteudística duplicaria os lexemas. Poucos são os casos em que se pode ver uma analogia. Coseriu cita como exemplo as denominações das árvores frutíferas. Os significados representam abstrações de coisas concretas e pensadas. Os elementos semânticos gramaticais, para mencionar o outro extremo, se definem igualmente por meio de referentes, mas de maneira indireta. Parecem princípios gerais que ordenam o mundo, como por exemplo masculino e feminino, possibilidade e realidade, ativo e passivo, sujeito e 
objeto, estado e atividade etc., enfim, noções gerais que parecem estruturar o conjunto de um grande grupo de significados, mas que não abrangem os sentidos lexicais.

Ora, podemos comprovar que a semântica, como área da lingüística, começou essencialmente baseada no referente-realidade e não no referente-categoria, isto é, nos elementos gramaticais, que Coseriu chama de funções, e nos derivativos. Mas temos de lembrarnos de que havia, desde os neogramáticos dos anos sessenta do século XIX, um recurso semântico que parecia abranger os dois lados do referente e que desempenhava um papel muito importante na busca das causas da evolução linguiística. Este recurso foi a já mencionada analogia. A analogia pode ser a causa de uma mudança gramatical, por exemplo no uso de certa forma "irregular", mas também de uma mudança fonética num lexema inexplicável de outra maneira.

Um dos motivos principais da introdução da semântica como área autônoma foi provavelmente a etimologia e as dificuldades crescentes que surgiram depois de estabelecidos e consagrados os étimos "inequívocos", "seguros". Sobraram numerosos casos duvidosos e, como o conhecimento da gramática histórica já não bastava para tornar plausível a origem de certas palavras, houve a necessidade de recorrer, na argumentação, a explicações semânticas. Enfim, a etimologia e a gramática histórica se inter-relacionavam. Sem novas pesquisas num dos dois ramos da linguiística, o outro também se estagnava.

Parece imprescindível levar em conta esta conjuntura particular na criação da semântica como nova subdisciplina linguiística. Se a semântica nasceu como matéria da linguiística histórica, foi porque se constituiu como uma subdisciplina suplementar e "ancilar" dos outros estudos linguiísticos da época. Daí a preocupação dos primeiros semanticistas com a sistematização dos processos evolutivos, com a pergunta de se seria possível estabelecer leis semânticas comparáveis às leis fonéticas. Daí também as hipóteses de eventuais analogias que, na etimologia, só se podiam basear em possíveis associações com outras palavras semanticamente relacionáveis. Daí finalmente o enfoque 
quase exclusivamente lexical e o declínio da semântica histórica lexical por causa da perda de interesse nos estudos etimológicos.

Se a semântica não fosse, em certa medida, um subproduto dos estudos etimológicos e da gramática histórica, a sua evolução no decorrer do século XX teria sido outra. Talvez possa dizer-se que a semântica desenvolvida sob outros postulados epistemológicos, como o estruturalismo e o gerativismo, não teria compartilhado o destino da semântica histórica, correndo atrás e não precedendo estas novas tendências.

Como abordar então a semântica de forma geral em vista da sua história particular? Seguindo o modelo de certas introduções à linguiística, seria aconselhável analisar o lado significativo das diferentes unidades da língua, a começar com os morfemas. Teríamos, então, uma semântica dos morfemas subdivisível em três semânticas parciais: a do morfema flexivo, a do morfema derivativo e composicional e a dos lexemas. Passar-se-ia depois a uma semântica dos sintagmas e das orações, para se chegar, finalmente, ao nível das unidades do texto e do discurso.

Seria de esperar que a semântica histórica tivesse levado em conta os diferentes níveis de análise da linguiística, isto é, disporíamos de uma semântica morfológica, de uma semântica lexical, de uma semântica sintática e finalmente de uma semântica do texto ou textual. Mas, devido à sua história particular acima esboçada, ela tomou outro rumo e ameaçou extinguir-se com as novas correntes da linguiística.

Para dar uma visão de conjunto da semântica diacrônica, podese partir também do início de seu estudo, isto é, perguntar pelas origens do estudo das unidades significativas da língua no século passado. Quais foram as razões que levaram ao enfoque semântico na pesquisa das línguas e quais os resultados que se esperavam? Como já expusemos, ver-se-ia o alto grau de dependência dos primeiros estudos semânticos das principais áreas de interesse daquela época: a fonética histórica e a etimologia. 
Filologia e Lingüística Portuguesa, n. 2, p. 61-79, 1998.

Mas pode-se, igualmente, tomar como ponto de partida a dicotomia saussuriana entre diacronia e sincronia e comprovar que a ocupação com a semântica se iniciou enquanto ciência histórica, passando, mais tarde, para um enfoque exclusivamente sincrônico.

Quem tentasse esboçar uma síntese das pesquisas semânticas desde os seus inícios científicos no século XIX até hoje, verificaria que estes três pontos de vista, ou seja, o histórico, o decorrente dos diferentes níveis de análise - o morfológico, o léxico, o oracional, etc. - e o metodológico relativo às duas perspectivas, a diacrônica e a sincrônica, se entrelaçam: a semântica como disciplina parcial da linguiística surgiu como uma tendência de afastar-se do aspecto exclusivamente formal, quer dizer, da preferência dada à pesquisa dos elementos fonéticos e morfológicos da língua. Isto ocorreu bem antes do enfoque semiótico da língua, ou seja, antes da definição do signo linguíístico por Saussure. É por isso que temos no início uma ciência das acepções e não dos significados. E é por isso que no começo havia uma metodologia classificadora inspirada pela retórica e pela psicologia e não pela concepção da língua como um conjunto estruturado.

A primeira etapa da linguiística científica, que abrange a maior parte do século XIX, caracteriza-se por uma preocupação com o que mais tarde Saussure ia chamar o lado significante da língua e por uma concentração nos significantes "mais significativos" da língua: os lexemas. A fonética, a morfologia, particularmente a morfologia flexiva, a sintaxe e a etimologia estavam no centro do interesse dos linguiistas. No que respeita à morfologia flexiva e derivativa, seu lado semântico interessava pouco, uma vez que estes tipos de morfemas tinham um lado significativo antes categorial. Nas pesquisas histórico-comparativas, o interesse "semântico" se limitava, via de regra, a verificar se a afinidade formal se baseava na identidade categorial ou funcional do elemento em questão. Dito em outras palavras: o parentesco morfológico entre duas línguas se comprovava mais facilmente, se se podia alegar a coincidência funcional.

Também na sintaxe, o critério semântico desempenhava um papel verificador: ou uma construção sintática do latim havia perdurado 
ROTH, Wolfgang. A semântica histórica: um campo abandonado da lingüística?

nas línguas românicas, ou - no caso de uma construção nova - surgia a necessidade de verificar se esta construção já existia em latim - embora lá tivesse outra função - e tornar compreensível o processo de substituição.

Onde uma semântica mais elaborada se revelou imprescindível, foi na etimologia, especialmente na etimologia das línguas românicas. Sobretudo nas grandes áreas lexicais mal documentadas no latim falado, ou na adoção de novos lexemas que representavam conceitos pósromanos, era preciso recorrer ao que se poderia chamar a plausibilidade semântica. E para essa plausibilidade se precisava de todo um aparato de "regras" semânticas comparável ao aparato histórico-fonético.

Ora, a semântica da palavra, ou melhor dito do lexema, que durante tanto tempo dominou os estudos da significação, revelou-se uma área muito difícil para qualquer sistematização. A semântica tradicional começou, por assim dizer, pelo lado mais difícil. Constituía um campo totalmente oposto à fonética histórica. A razão deste fato encontra-se no caráter sui generis do morfema lexical. É este o signo linguíístico mais intimamente relacionado com o que a linguística costuma chamar, por falta de uma terminologia mais adequada, a realidade extralingüística. O conhecido triângulo de Ogden e Richards nos ilustra este estado de coisas. E sabemos que esta realidade, por enquanto, se deixa estruturar apenas parcialmente. Se fosse completamente estruturável, os funcionários das grandes bibliotecas do mundo já teriam encontrado uma ordem satisfatória dos seus acervos. Mas infelizmente não é bem assim. As diferentes tentativas de ordenar o léxico de acordo com o campo ou o assunto, os chamados dicionários ideológicos, sempre toparam com graves obstáculos. Prefere-se, para uma melhor orientação, acrescentar um índice alfabético, o que praticamente significa o fracasso da sistematização a partir do significado. Explica-se desta maneira que os estudos semânticos inspirados pelo estruturalismo tivessem de limitar-se a áreas relativamente bem restritas. $\mathrm{O}$ otimismo, que às vezes insinuam os semanticistas, de um dia poder sistematizar-se todo o vocabulário de uma língua histórica, não se tem concretizado. 
Filologia e Lingüística Portuguesa, n. 2, p. 61-79, 1998.

Mas a semântica lexical histórica se defronta, para sua sistematização, também com outros fatores. Sem poder enumerar a todos, sejam mencionados aqui apenas:

- o caráter ambíguo da palavra que se concretiza na polissemia;

- o co-texto, p. ex. co-texto gramatical (cf. nada, uma ova, franc. pas, point, goutte);

- o contexto ou âmbito (situacional, social, profissional);

- a intenção enunciativa;

- a variação interna da língua (cf. abacaxi);

- o referente (democracia, pluma);

- a necessidade denominativa (catacrese) (ao pé da montanha, janela no computador).

Por outro lado, a semântica lexical histórica foi mais além da lingüística propriamente dita. Sociólogos como Matoré ou estudiosos da história das idéias, que se baseiam na evolução do significado de certas palavras, as chamadas palavras-chave, aproveitam-se dos resultados tradicionais da semântica lingüística para as suas pesquisas.

A semântica tradicional, isto é, a semântica histórica com enfoque especial no léxico, vacila essencialmente entre os dois pontos do triângulo de Ogden e Richards, entre o significado e o referente. Se a linguiística saussuriana insiste em limitar a linguística à linguagem propriamente dita, não admitindo o chamado extralinguiístico, o fato de o referente estar intimamente ligado ao significado sempre tem motivado os lingüistas a incluir o não-linguiístico nos estudos da semântica. Assim, podemos distinguir uma semântica do significado e uma semântica na qual, além do estudo do significado, se estuda a realidade que está atrás do significado. Podemos comprovar que as primeiras tentativas de fazer do estudo da significação um estudo rigorosamente linguístico se baseavam essencialmente em princípios puramente linguiísticos. É a fase da classificação chamada de lógica que se iniciou já antes da primeira obra semântica científica de Michel Bréal, considerado o fundador deste ramo da linguiística. É claro que nestes pri- 
meiros esforços classificatórios o estudioso estava obrigado a recorrer a critérios que não fossem puramente linguiísticos, já que a semântica tratava de elementos significativos e não podia orientar-se pela epistemologia linguística relativa aos elementos não-significativos, isto é, os fonemas. Mas como a ciência etimológica não podia restringir-se a uma mera discussão da evolução fonética, mas tinha de levar em conta o significado das palavras de que tratava e a realidade chamada de extralinguiística subjacente, a semântica histórica teve de estabelecer algo como um fio condutor que ia orientar a explicação da mudança semântica. Para isso se prestava a retórica, que dispunha de duas vantagens. Representava um campo em que se podia ver de perto, nas chamadas figuras lexicais, o fenômeno dos processos criativos do lado significativo da língua, ou melhor dito, da fala, e se apoiava numa bibliografia consagrada em que já se haviam descrito estes processos de forma bastante metódica. Assim, foi quase natural que a retórica tivesse dado o modelo para a descrição das mudanças semânticas. Constituiu-se, portanto, a chamada classificação lógica, que ia ter grande repercussão durante toda a primeira metade do século XX.

A segunda grande corrente na semântica histórica tradicional é a chamada psicológica, na qual se distinguem duas correntes: uma individualista, que se dedicava aos processos psíquicos que se realizam no falante, a outra de psicologia coletiva, que partia tanto dos estudos da associação já em debate em fins do século XIX, como na chamada psicologia dos povos. É esta última que, com a obra de Wilhelm Wundt, em fins do século XIX, nos deu uma súmula das aspirações da semântica do século XIX dedicada especialmente ao problema de uma possível regularidade na evolução semântica comparável à evolução fonética.

Sabemos que as teorias estruturalistas, assim como as idéias da gramática gerativa, fizeram estagnar a semântica histórica. Os trabalhos que temos a partir dos anos vinte do século XX refletem os grandes projetos da semântica histórica, acrescentando novas idéias, mas principalmente resumindo e completando as idéias anteriores. 
Assim, chegou-se, nos anos cinquienta e sessenta, às duas grandes obras de Stephen Ullmann de visão geral da semântica histórica e diacrônica: Précis de sémantique française e Princípios da Semântica. O capítulo neste último livro sobre a semântica histórica não é só uma síntese dos estudos anteriores a respeito: mostra ao mesmo tempo o método dos semanticistas tradicionais, que se distinguem por seu detalhismo. É interessante indicar que, ao que eu saiba, uma publicação dos anos oitenta deste século adota, sem maiores reservas, os métodos elaborados pelos semanticistas clássicos. É um livro sobre a lexicogenética, isto é, a criação de neologismos, do inglês. Esta obra contém um longo capítulo sobre o que o autor chama evidentemente não-influenciado pela semântica de Silveira Bueno a metassemia. Com este termo o autor designa a semântica evolutiva com enfoque nos seus processos criativos ou produtivos. Tudo o que se escreveu depois em termos de semântica histórica toma como ponto de partida estes dois trabalhos. Nas suas partes diacrônicas, os livros de Ullmann representam um corte na semântica lexical, corte que durante alguns anos deu a impressão de que nada de novo podia ser acrescido em termos de semântica histórica e que fez com que os estudos semânticos com inclusão do referente saíssem da visão geral dos estudos semânticos.

O estruturalismo coincidiu, como se sabe, com uma marcada ênfase na linguiística sincrônica. Na sua variante linguiística, a saber, a pesquisa do campo léxico ou semântico, pareceu dar uma solução ao problema da definição científica do que se entende por significado ou sentido, depois de, nos anos vinte e trinta, se terem generalizado idéias avessas ao estudo da significação (Weisgerber, teoria behaviorista). Poucas são as contribuições diacrônicas, entre as quais se destaca o famoso artigo de Eugenio Coseriu intitulado "Por uma semântica diacrônica estrutural".

Se tentarmos dar uma visão geral, mesmo que seja superficial, podemos talvez distinguir cinco correntes ou tendências na semântica histórica pós-estruturalista: 
ROTH, Wolfgang. A semântica histórica: um campo abandonado da lingüística?

1. A semântica histórica enquanto processo criativo de palavras (Tournier).

2. A semântica histórica das palavras-chave e dos conceitos (Matoré, Stierle).

3. A semântica psicológica baseada na linguística cognitiva e na teoria dos protótipos (Geeraerts, Peter Koch).

4. A semântica histórica de fragmentação (Klein).

5. A semântica não-lexical (oracional, do discurso) (Busse).

Neste ensaio não será possível tratar das cinco correntes. Para caracterizá-las sucintamente, pode-se dizer que a tendência número 1 praticamente está baseada na semântica histórica tradicional, sobretudo na chamada classificação lógica.Tournier, no seu livro sobre lexicogenética do inglês contemporâneo, serve-se dos resultados da semântica histórica, aplicando-os a uma sistematização dos processos criativos do léxico que o autor chama de lexicogenética. $O$ novo consiste em que Tournier tenta limitar-se à produtividade na criação de novos significados. Para distinguir a semântica histórica tradicional da semântica produtiva, ele chama esta última de metassemia, termo que conhecemos do "Tratado de semântica" de Silveira Bueno, mas usado aqui em outro sentido.

A tendência número 2 já conta com uma longa tradição. Os trabalhos de Georges Matoré partem da idéia de que, para caracterizar uma época, é preciso partir de certas palavras-chave. Analisar o emprego e a frequiência destas palavras pode facilitar a compreensão das tendências e das idéias da respectiva época. Trata-se antes de estudos "estáticos", e seria preciso comparar várias, ou pelo menos duas fases históricas para que seja realmente um estudo diacrônico. É o que tenta recuperar Stierle num artigo, que se tornou bastante conhecido e que se inspira antes no idealismo do que em idéias sociolinguiísticas. No caso do famoso trabalho de Dubois sobre o vocabulário da Comuna, temos outro enfoque histórico "estático" baseado no método estruturalista. 
Filologia e Lingüística Portuguesa, n. 2, p. 61-79, 1998.

Os trabalhos de Dietrich Busse constituem o início de uma semântica lexical que se enquadra na linguística do discurso. Aqui o lexema se vê no seu contexto linguiístico. As idéias de Busse, por enquanto, dificilmente se integram na linguiística. Representam antes uma tentativa de interpretação de textos históricos pelo critério do emprego de palavras-chave.

Todas estas tendências, inclusive as que serão discutidas adiante, se caracterizam pelo fato de expressamente levarem em conta o referente. Em alguns desses trabalhos, sobretudo os da escola sociológica francesa (Matoré, Dubois), o estruturalismo, é certo, constitui uma base metodológica. Mas, como se tem dito, o estruturalismo semântico - com exceção do famoso trabalho de Coseriu citado - temse revelado pouco propício ao estudo de questões históricas. Isto se deve a duas particularidades do estruturalismo: a restrição ao linguiístico propriamente dito, o que significa em parte a exclusão do referente, e ao caráter estático de seu método. Podem-se comparar duas fases cronológicas e pôr em relevo as diferenças, mas é difícil explicar como as diferenças entre dois "cortes temporais" nasceram, quais as causas e qual a dinâmica. Parece que, sem recorrer ao referente, qualquer semântica histórica lexical está condenada a uma visão restrita.

Das cinco tendências acima mencionadas, podemos dizer que duas se aproximam mais da semântica histórica: a linguiística cognitiva, e a teoria dos protótipos que dela decorre, e a semântica de fragmentação.

A teoria dos protótipos faz parte da linguiística cognitiva, que por sua parte se dedica à descrição e à explicação das estruturas e processos linguiísticos mentais. De acordo com Geeraerts, línguas naturais mostram uma tendência para desenvolver complexos polissêmicos. O núcleo da teoria dos protótipos se baseia na idéia de que diferentes acepções podem ter um peso diferente e que este fato pode influir no mecanismo semântico. Como exemplo, cita-se em várias introduções o sentido de pássaro/ave ("bird"). Neste hiperônimo lexemas como pardal ou, na Europa, melro têm um peso muito maior do que avestruz ou pingüim. Esta observação se confirma pela história das 
línguas românicas, onde a palavra latina PASSER "pardal" começou a usar-se para designar o que era AVIS. Como na semântica histórica clássica, parte-se da suposição de que línguas naturais mostram uma tendência para desenvolver complexos polissêmicos. Já Michel Bréal havia salientado a importância da polissemia. Polissemia e mudança semântica são apenas as duas faces da mesma medalha: o que para a semântica sincrônica é a polissemia, para a semântica diacrônica é a mudança de significado. De acordo com Geeraerts, o caráter prototípico é uma forma de eficiência conceptual. A outra é o esforço por eliminar a polissemia.

A teoria dos protótipos está intimamente ligada ao referente, isto é, ao saber enciclopédico das pessoas. "The distinction between semantic and encyclopedic information fades away" (Geeraerts de acordo com Koch, 1995, p. 34). Esta teoria tende a negligenciar o significado em prol do referente (Koch, 1995, p. 37). Se o referente é o que se costuma chamar de "realidade extralinguística", esta realidade se acentua também mentalmente. A metáfora como processo metassêmico se baseia na similitude referencial. Koch $(1995$, p. 39) cita o exemplo da palavra tubarão, que no sentido metafórico pode designar, em diferentes línguas, uma pessoa rica, poderosa e ávida, que busca o seu lucro sem escrúpulos. Aqui, no que respeita ao referente, pensa-se em determinadas espécies de tubarões que podem ser perigosas para 0 homem, e menos aqueles que não constituem uma ameaça para o ser humano. Também na metonímia se trata de uma relação de contigüidade no nível do referente.

Alguns lingüistas, como Peter Koch, introduzem o termo designado. O designado é a representação mental da coisa extralinguiística e, portanto, uma representação enciclopédica. A teoria dos protótipos e, com ela, a linguiística cognitiva trata de pesquisar a relação entre o significado lexical e as unidades conceptuais apelando para a capacidade humana de categorização. No que respeita à semântica histórica, parte-se da existência de determinadas "vias evolutivas" impostas pelo saber enciclopédico, o que faz com que o significado apareça numa certa moldura (inglês: "frame"). Estas "vias evolutivas" não devem ser confundidas com "regularidade". 
Filologia e Lingüística Portuguesa, n. 2, p. 61-79, 1998.

Um caso típico de frame, para dar um exemplo que me ocorreu, é a mudança semântica da palavra MONETA do latim para os diferentes sentidos nas línguas européias: moeda em português, etc. É só mediante o recurso ao frame que se pode explicar a evolução de admoestadora para peça de moeda, que fora desta moldura não teria nenhum sentido. Esta teoria do frame torna extremamente difícil estabelecer a teoria de uma evolução "regular" na mudança de significado.

Infelizmente não é possível entrar em detalhes, mas penso que estas poucas idéias que acabo de expor mostram certos novos - e ao mesmo tempo - velhos rumos da semântica histórica, a saber:

- a volta ao estudo da palavra, sendo esta a unidade mais densamente significativa dos elementos linguiísticos;

- o apelo a certas idéias fundamentais da semântica histórica como, por exemplo, a importância da polissemia e da psicologia associativa, bem como da psicologia social (Wundt: psicologia dos povos);

- a importância do referente e da representação mental do referente (designado);

- o saber enciclopédico do falante;

- o reconhecimento da existência de "vias conceptuais" que levam ao postulado de universais evolutivos na semântica;

- a negação definitiva da equiparação de leis semânticas de acordo com o modelo da fonética histórica.

Os rumos tomados pela semântica moderna, sobretudo a semântica lexical, inspiraram um jovem professor de filologia românica a arriscar-se num campo durante muito tempo negligenciado por essa matéria. Refiro-me ao livro recentemente publicado por Franz-Josef Klein intitulado Bedeutungswandel und Sprachendifferenzierung. Die Entstehung der romanischen Sprachen aus wortsemantischer Sicht ("Mudança semântica e diferenciação de línguas. A origem das línguas românicas na perspectiva da semântica lexical”). 
ROTH, Wolfgang. A semântica histórica: um campo abandonado da lingüística?

Citamos, para terminar, a passagem de um livro que teve muita repercussão na linguiística das primeiras décadas do século XX.

Cito, no que segue, a tradução espanhola:

"Es de prever la constitución de una semántica general que, centralizando los datos recogidos en cada lengua sobre los cambios de sentido, permitirá reducirlos a pocos principios, no desde el punto de vista simplesmente lógico, como ha hecho hasta aquí, sino desde el punto de vista psicológico. Al fin, debería tenderse, partiendo no de las palabras, sino de las ideas que expresan" (Vendryès, 1958 (1967) p. 236). Sem poder prever o rumo que a semântica histórica ia tomar e a prostração em que ficou tanto tempo, Vendryès, o autor destas linhas, mostra com esta observação que uma semântica lexical histórica não pode desenvolver-se numa linguiística limitada ao que - durante muito tempo - se pensou fosse o único objeto desta ciência. Este ramo da linguíística está intimamente relacionado com a função comunicativa da linguagem humana e o fato de este aspecto não raro ter sido marginalizado por certas correntes da linguiística evidentemente fez com que demorasse o que talvez agora estejamos presenciando: um ressurgimento da semântica histórica.

\section{BIBLIOGRAFIA}

AUSTIN, J. L. (1975) Die Bedeutung eines Wortes. In AUSTIN, J. L. Wort und Bedeutung. München, p. 11-36.

BARRERA LINARES, L. (1995) Texto y contexto de la comunicación literaria: el caso venezolano de Osvaldo Trejo. In Iberoamericana, 19, p. 76-92.

BATCHELOR, R. E. (1994) Using Spanish synonyms. Cambridge, Cambridge University Press, vol. VIII.

BAYLON, C. \& MIGNOT, X. (1995) Sémantique du language. Initiation. Paris, Nathan.

BLANKE, G. H. (1973) Einführung in die semantische Analyse. München.

BRÉAL, M. (1897) Essai de sémantique. Paris.

(1964) Semantics. Studies in the science of meaning. New York.

BUENO, S. (1965) Tratado de semântica brasileira. 4. ed., São Paulo, Saraiva. 
Filologia e Lingüística Portuguesa, n. 2, p. 61-79, 1998.

BUSCH, I. (1993) Überlegungen zur semantischen Beschreibung eines lexikalischen Feldes (spanische Verben des Besitz- und Verfügungswechsels ...). In LUTZEIER, Peter Rolf (org.) Studien zur Wortfeldtheorie. Tübingen, Niemeyer.

BUSSE, D. (org.) (1991) Diachrone Semantik und Pragmatik: Untersuchungen zur Erklärung und Beschreibung des Sprachwandels. Tübingen, Niemeyer, vol. VI, 277 S. (= Reihe germanistische Linguistik 113)

(1987) Historische Semantik. Analyse eines Programms. Stuttgart, Klett-Cotta.

(1993) Juristische Semantik. Grundfragen der juristischen Interpretation in sprachwissenschaftlicher Sicht. Berlin, Duncker \& Humblot.

BUßMANN, H. (1990) Lexikon der Sprachwissenschaft. 2. ed., Stuttgart, Kröner.

CORRALES ZUMBADO, I. (1981) El campo semántico ‘edad’ en español. Santa Cruz de Tenerife.

COSERIU, E. (1956) La creación metafórica en el lenguage. Montevideo, Universidad de la República.

(1964) Pour une sémantique diachronique structurale. Travaux de Linguistique et de Littérature, 2, 1, p. 139-86.

DEL MAR GARACHANA, M. e HILFERTY, J. (1994) Una representación de la polisemia en diacronía y sincronía. Anuari de Filologia, Secció F: Estudios de lengua y literatura españolas, 17, 5, p. $71-92$

DIECKMANN, W. (1969) Sprache in der Politik. Einführung in die Semantik und Pragmatik der politischen Sprache. Heidelberg.

ESCOBEDO RODRIGUEZ, A. (1992) El campo léxico 'hablar' en español. Granada.

ESPAÑOL GIRALT, T. (1991) Las funciones clasificadora y no restrictiva del adjetivo en español. Anuari de Filologia, Secció F: Estudios de Lengua y Literatura Españolas, 14, 2, p. 9-20.

Estudios de lexicología y metalexicología del español actual. (1992) Tübingen, Niemeyer.

FERNÁNDEZ, F. M. (recopilador) (1994) Lecturas de semántica española. Alcalá de Henares, Universidad.

FERNÁNDEZ GONZÁLES, A. R., HERVÁS, S. e BÁEZ, V. (1989) Introducción a la semántica. Madrid, Cátedra.

GARCÍA ASENSIO, M. Á. e YÚFERA GÓMEZ, I. (1993) Sobre la evolución semántica de algunas palabras del español que designan unidades de comunicación verbal. Revista Española de Lingüística, 23, 2, p. 359-73.

GECKELER, H. (1994) Semántica estructural y teoria del campo léxico. Madrid, Gredos. (1971) Strukturelle Semantik und Wortfeldforschung. München, Fink.

GREIMAS, A. J. (1987) Semántica estructural. Madrid, Gredos.

GUIRAUD, P. (1994) La semántica. México, Fondo de Cultura Económica.

GUTIÉRREZ ORDÓÑEZ, S. (1992) Introducción a la semántica funcional. Madrid, Síntesis.

HEERDEGEN, F. (1890) Lateinische Semasiologie. Berlim, S. Calavary \& CO.

HENNE, H. (1972) Semantik und Lexikographie. Berlim/New York. 
ROTH, Wolfgang. A semântica histórica: um campo abandonado da lingüística?

ILARI, R. e GERALDI, J. W. (1995) Semântica. 3. ed. São Paulo, Ática.

KLEIN, F.-J. (1997) Bedeutungswandel und Sprachendifferenzierung. Tüibingen, Niemeyer.

KOCH, P. (1995) Der Beitrag der Prototypentheorie zur historischen Semantik, Eine Britische Bestandsanfnahme. Romanitisches Jahrbuch, 46, p. 27-46.

KÖRNER, K.-H. (1977) Einführung in das semantische Studium des Französischen. Darmstadt, Wissenschafrliche Buchgesellschaft.

LYONS, J. (1995) Linguistic semantics. An introduction. Cambridge, Cambridge University Press.

MARQUES, M. H. D. (1990) Iniciação à semântica. Rio de Janeiro, Jorge Zahar.

MATORÉ, S. (1953) La méthode en lexicologie. Paris, Didier.

MEILLET, A. (1975) Linguistique historique et linguistique générale. Paris, Champion.

PAUL, H. (1968) Prinzipien der Sprachgeschichte. Darmstadt, Wissenschaftliche Buchgesellschaft.

POTTIER NAVARRO, H. (1991) La polisemia léxica en español. Teoría y resolución. Madrid, Gredos.

RESTREPO FÉLIX, S. J. (1967) Diseño de semántica general. El alma de las palabras. Cali, Col., Ed. Norma.

SABBAN, A. (1994) Polysemie und kognitive Semantik am Beispiel französischer und spanischer Verben. Zeitschrift für französische Sprache und Literatur, 104, 3, p. 227-51.

SALVADOR, G. (1985) Semántica y lexicología del español. Madrid, Paraninfo.

SCHMIDT, E. (1967) Lexikalische und aktuelle Bedeutung. Ein Beitrag zur Theorie der Worbedeutung, 4. Aufl., Berlin.

SECO, M. (1987) Estudios de lexicografía española. Madrid, Paraninfo.

SERRANO VÁZQUEZ, M. del C. (1994) La semántica de los objetos: una posible organización del vocabulario de las greguerías de Ramón Gómez de la Serna. Verba, 21, p. 417-38.

SILVA JÚNIOR, P. da (1903) Noções de semântica. Rio de Janeiro, Francisco Alves.

SILVA-CORVALÁN, C. (1995) Contextual conditions for the interpretation of poder and deber in Spanish. In Modality in grammar and discourse, p. 567-605.

TAMBA-MECZ, I. (1989) La semántica. Barcelona, Oikos-Tau.

TOURNIER, J. (1985) Introduction descriptive à la lexicogénétique de l'anglais contemporain. Paris-Genève, Champion-Slatkine.

TRIER, J. (1931) Der deutsche Wortischatz im Sinnbezirk des Verstandes. Die Geschichte eines sprachlichen Feldes. Heidelberg, Winter.

TRUJILLO, R. (1970) El campo semántico de la valoración intelectual en español. Las Palmas. (1976) Elementos de semántica lingüística. Madrid, Cátedra.

(1988) Introducción a la semántica española. Madrid, Arco/Libros.

ULLMANN, S. (1977) Semântica. Uma introdução à ciência do significado /Semantics, an introduction to the science of meaning/. 4. ed. Lisboa, Fundação Calouste Gulbenkian.

VENDRYES, J. (1958) El lenguaje. Introducción lingüística a la historia. Trad. M. de Montoliu etc. México, D.F., Unión Tipográfica Editorial Hispano Americana. 
Filologia e Lingüística Portuguesa, n. 2, p. 61-79, 1998.

WIEGAND, H. E. (1976) Synonymie und ihre Bedeutung in der einsprachigen Lexikographie. In MOSER, H. (org.) Probleme der Lexikologie und Lexikographie. Dusseldorf.

SCHMIDT, L. (org.) (1973) Wortfeldforschung. Darmstadt, Wissenschaftliche Buchgesell-schaft. WUNDT, W. (1904) Völkerpsychologie. 1 Band: Die Sprache, 2 Teile, Leipzig. 2. Aufl.

ABSTRACT: A definition of the field of semantics is attempted, approaching its development from the earliest studies, in connection with those of etymology as well as with those of classical grammar. Reasons are given for the prevalence of the lexical approach in traditional semantics, and the question of the referent, excluded in structuralist studies but reintroduced in contemporary theories, is also taken into account. An approximation with classical semantics is arrived at from the exams of the most significant contemporary trends, with emphasis on prototype theory as part of cognitive linguistics. Evolutionary paths are seen as based on encyclopedic knowledge as well as on the human ability of categorization. The concern of classical semantics with the lexicon and with polysemy is reconsidered and situated within the communicative function of language.

Keywords: meaning/ signification, referent, lexical semantics, historical semantics. 